\title{
The atlas of structural geometry: a digital collection of 25 years of analogue modelling
}

\section{D.A. Nieuwland and M. Nijman}

\author{
Vrije Universiteit, Earthsciences, De Boelelaan 1085, 1081 HV Amsterdam, \\ The Netherlands. Tel.: +31-(0)20-4447422, e-mail: nied@geo.vu.nl. \\ ${ }^{2}$ Madelon Nijman: Shell Research and Technology, P.O.Box 60, 2280AB Rijswijk, \\ The Netherlands. Tel.: +31-(0)70-3113385, e-mail: m.nijman@siep.shell.com
}

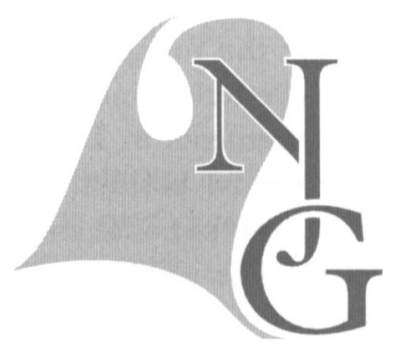

\section{The CD-ROM}

Analogue model experiments of tectonic faulting have been carried out at the Shell Research lab, then 'KSEPL', since 1974. During the following years hundreds of experiments, covering all the tectonic regimes, were performed. In order to provide Shell geologists and seismic interpreters with easy access to this vast amount of data, an interactive CD-ROM has been made. The $\mathrm{CD}$ has now been made available to the geoscience community outside Shell and can be used as any other publication. It contains examples of analogue models, illustrating geometry, fault topology and kinematics of all tectonic regimes together with seismic examples, outcrop photo's, satellite images, 3D computed tomography scans and video-laser surface scans. Examples of modern analytical techniques such as fault extraction and curvature analysis together with $3 \mathrm{D}$ visualization complete the picture. Example pictures may be extracted from the $\mathrm{CD}$, but can only be used in publications after permission has been obtained from Shell Rijswijk.

The tectonic spectrum forms a clear, almost intuitive basis for sixty selection buttons. A few topics that cannot be covered in the spectrum such as diapirism are present as separate buttons (in the form of pebbles). As a consequence of the long time-span covered by the experiments, not all the examples shown here represent the latest techniques and views. However, we believe that this CD-ROM will provide you with an enjoyable means to quickly browse through a unique collection of experimental examples of tectonic styles collected during twenty-five years of modelling work.

\section{The tectonic spectrum}

In the tectonic spectrum (originally designed by Angus $\mathrm{McC}$ oss) all the tectonic regimes can easily be represented in graphic form. The basis of the spectrum is a small central circle, representing an element in the earths crust. Let this circle move in an upward direction (north) this will lead to compression in front of the circle, to extension behind the circle and to strike-slip on either side of the circle. As the structures associated with this deformation are symmetric relative to left and right, each half is used for a different purpose. The left half of the circle is used to represent thin-skinned tectonics, i.e. not including basement, the right half is used to represent thick-skinned or basement controlled tectonic structures. The design of the tectonic spectrum makes it possible to navigate intuitively through the various tectonic regimes and quickly find your specific region of interest with the relevant information logically organised.

\section{How to use the CD-ROM}

The CD is constructed around the tectonic spectrum. A series of concentric rings contains various types of information, which can be accessed simply by selecting the desired segment. The outermost ring indicates the tectonic style, the next ring inwards con- 
tains a general introduction to the style of the segment, the following ring contains examples of experiments, next are seismic and outcrop examples (if available), next are examples of fault analysis and the most central ring contains examples of trap-styles related to the tectonic style of the selected segment.

Not all the tectonic fault systems can be captured in the spectrum. These can simply be found on the pebbles, by selecting with double a mouse click.

\section{Contacts}

Should one need more information, Dick Nieuwland or Madelon Nijman can be contacted at the following addresses: Dick Nieuwland, Vrije Universiteit, Earthsciences, De Boelelaan 1085, 1081HV Amsterdam,
The Netherlands. Tel.: +31-(0)20-4447422, e-mail: nied@geo.vu.nl.

Madelon Nijman: Shell Research and Technology, P.O.Box 60, 2280AB Rijswijk, The Netherlands.

Tel.: +31-(0)70-3113385, e-mail:

m.niiman@siep.shell.com.

\section{Acknowledgements}

Permission of Shell Research and Technology in Rijswijk The Netherlands, to publish this CD-Rom is gratefully acknowledged. Many researchers and students on stage at Shell have contributed to this $C D$, All are gratefully thanked and mentioned at the closure of the $\mathrm{CD}$. 